\title{
Subgroup analyses of the effectiveness of oral glucosamine for knee and hip osteoarthritis; a systematic review and individual patient data meta-analysis from the OA Trial Bank
}

Runhaar J, Rozendaal RM, van Middelkoop M, Bijlsma JW, Doherty M, Dziedzic KS, Lohmander LS, McAlindon TE, Zhang W, Bierma-Zeinstra S

\author{
Runhaar J (corresponding author) \\ Post-doctoral Researcher \\ Erasmus University Medical Center Rotterdam \\ Department of General Practice \\ Room NA19-06 \\ PO-box 2040, 3000 CA Rotterdam, the Netherlands \\ j.runhaar@erasmusmc.nl
}

\section{Rozendaal RM}

Post-doctoral Researcher

Erasmus University Medical Center Rotterdam

Department of General Practice

PO-box 2040, 3000 CA Rotterdam, the Netherlands

van Middelkoop M

Assistant Professor

Erasmus University Medical Center Rotterdam

Department of General Practice

PO-box 2040, 3000 CA Rotterdam, the Netherlands

Bijlsma JW

Professor of Rheumatology

University Medical Center Utrecht

Department of Rheumatology \& Clinical Immunology

PO-box 85500, 3508 GA Utrecht, the Netherlands

Doherty M

Professor of Rheumatology

The University of Nottingham, City Hospital

Academic Rheumatology Department

Hucknall Road NG5 1PB, Nottingham, UK

Dziedzic KS

Arthritis Research UK Professor of Musculoskeletal Therapies

NIHR Knowledge Mobilisation Research Fellow

Keele University

Department of Primary Care \& Health Services

Staffordshire ST5 5BG, United Kingdom

Lohmander LS

Professor of Orthopaedics

Lund University

Medical Faculty, Department of Clinical Sciences, Orthopaedics

22185 Lund, Sweden

McAlindon TE

Professor of Medicine 
Tufts Medical Center

Division of Rheumatology

800 Washington Street, Boston, MA, 02111 USA

Zhang W

Professor of Epidemiology

The University of Nottingham, City Hospital

Academic Rheumatology Department

Hucknall Road NG5 1PB, Nottingham, UK

Bierma-Zeinstra S

Professor of Osteoarthritis and Related Disorders

Erasmus University Medical Center Rotterdam

Department of General Practice and Department of Orthopaedics

PO-box 2040, 3000 CA Rotterdam, the Netherlands 


\section{Abstract}

Objective: To evaluate the effectiveness of oral glucosamine in subgroups of people with hip or knee osteoarthritis (OA) based on baseline pain severity, BMI, sex, structural abnormalities and presence of inflammation, using individual patient data.

Methods: After a systematic search of the literature and clinical trial registries, all randomized controlled trials (RCTs) evaluating the effect of any oral glucosamine substance in patients with clinically or radiographically defined hip or knee OA were contacted. As a minimum, pain, age, sex and BMI at baseline and pain as an outcome measure needed to be assessed.

Results: Of 21 eligible studies, six ( $\mathrm{N}=1663$ ) shared their trial data with the OA Trial Bank. Five trials (all independent of industry, $\mathrm{N}=1625$ ) compared glucosamine to placebo, representing $55 \%$ of the total number of participants in all published placebo-controlled RCTs. Glucosamine was no better than placebo for pain or function at short ( 3 months) and long-term ( 24 months) follow-up. Glucosamine was also no better than placebo among the predefined subgroups. Stratification for knee $\mathrm{OA}$ and type of glucosamine did not alter these results.

Conclusions: Although proposed and debated for several years, open trial data are not widely made available for studies of glucosamine for $\mathrm{OA}$, especially those sponsored by industry. Currently there is no good evidence to support the use of glucosamine for hip or knee OA and an absence of evidence to support specific consideration of glucosamine for any clinically relevant OA subgroup according to baseline pain severity, BMI, sex, structural abnormalities, or presence of inflammation.

Keywords: Osteoarthritis, glucosamine, individual patient data, meta-analysis, subgroups 


\section{Introduction}

Oral glucosamine has long been recommended for the treatment of knee and hip osteoarthritis (OA). However, recent guidelines by OARSI ${ }^{1}$ and NICE ${ }^{2}$ highlight the lack of support for the efficacy of oral glucosamine for the management of symptoms or disease modification in $\mathrm{OA}^{3}$. With increasing study quality over the past decades, reported effect sizes for glucosamine have decreased ${ }^{4}$. Furthermore, methodological issues in trials studying the effect of glucosamine for OA symptoms, such as inadequate allocation concealment and absence of intention-to-treat analyses, has resulted in overestimation of its effectiveness ${ }^{5}$. A network meta-analysis from 7 high-quality, large (>200 participants per trial) randomized controlled trials (RCTs) concluded that oral glucosamine was not superior to placebo in reducing OA pain or reduction in joint space narrowing ${ }^{3}$.

Notwithstanding the overall lack of efficacy of glucosamine, it is possible that certain subgroups of OA might respond differently (either better or worse) to any specific treatment ${ }^{6}$. These subgroups might be based on different pathologies underlying the clinical presentation of $O A$, different disease stages, or on the presence of different co-morbidities ${ }^{6}$. Accordingly, clinical guidelines increasingly call for the identification of any predictors of response to different treatment modalities ${ }^{7}$. Since the effectiveness of glucosamine varies among different populations ${ }^{4,5,8}$, it is possible that glucosamine might show higher efficacy when targeted at specific subgroups.

Recently, van Middelkoop et al. ${ }^{9}$ reported on the methodology and legal structure to perform individual patient data (IPD) meta-analyses to identify clinically relevant subgroups that may show differential response to different OA treatments (the OA Trial Bank). The proposed methodologically robust method tests subgroup-treatment interaction effects using IPD from multiple published trials and allows for adjustment for confounding at both study and individual patient levels ${ }^{9}$. Using this method, increased short-term efficacy for glucocorticoid treatment among knee OA patients with more severe pain has been demonstrated ${ }^{10}$.

The present study aimed to collect IPD of all RCTs performed for oral glucosamine in people with knee and hip OA to evaluate the efficacy within predefined subgroups of OA based on pain severity, $\mathrm{BMI}$, sex, structural abnormalities and presence of inflammation.

\section{Methods}

\section{Systematic search}

To identify all available RCTs, a systematic search of the literature was performed in Pubmed, the Cochrane Central Register of Controlled Trials, Embase, Web of Science, Cinahl and Scopus. The search strategy was based on the search protocol of the Cochrane publication on the effectiveness of glucosamine ${ }^{8}$. It was adjusted for the different databases and limited to publications from 1994 because of the likelihood of communicating with corresponding authors and data being available (searched up to March 2014 and available upon request). Reference lists were hand searched for further identification of published work. Additional potential on-going studies were searched for in clinical trial registries.

Two authors (JR and RR) independently selected citations based on titles and abstracts. Subsequently full articles were obtained for those citations thought to fulfil the inclusion criteria and were independently assessed by the two review authors. A third review author was consulted if consensus was not reached (MvM). No protocol was registered for the current project, but full protocol details for the systematic review and the IPD meta-analysis were pre specified in the data delivery license 
agreement, that was approved by all members of the OA Trial Bank Steering Committee before the systematic search of the literature was initiated (available upon request).

\section{Inclusion/exclusion criteria}

All RCTs evaluating the effect of any oral glucosamine substance in participants with knee or hip OA were included. This included studies testing the effects of glucosamine within a subgroup of participants with OA. Studies solely testing a combination of glucosamine with another substance (e.g. chondroitin) were not included. There was no language restriction.

\section{Participants}

Participants were men and/or women with a diagnosis of OA of the knee or hip:

(1) according to ACR classification criteria ${ }^{11}$, or

(2) on the basis of detailed clinical and/or radiographic information.

Studies including a subgroup of knee or hip OA patients were also included, because individual patient data were collected.

\section{Interventions}

All comparisons between different oral glucosamine doses or between different frequencies of intake were included. Co-interventions were allowed as long as they were identically applied to the glucosamine and control group.

\section{Comparator}

All comparisons between oral glucosamine and any placebo/medication/dietary supplement/other non-surgical treatment were included.

\section{Outcomes}

The minimum criterion for inclusion of RCTs was adequate reporting of pain as an outcome measure.

\section{Baseline predictors}

(1) Important data:

As a minimum, severity of pain, age, sex and BMI should have been assessed at baseline in order to define subgroups.

(2) If available:

Signs of inflammation, either by physical examination (warmth, effusion) or by additional testing (ultrasound, MRI, biopsy, serum CRP/ESR), and structural abnormalities by radiography or magnetic resonance imaging (MRI)at baseline.

\section{Data collection, transfer and checks}

All corresponding authors of eligible trials were approached and asked to share trial data (first by email, subsequently by telephone). When corresponding authors could not be reached, the other listed authors and the institutes in which the trials had been performed were contacted. All datadeliverers willing to participate (i.e. the research institutes who own the data) were asked to sign the data delivery license agreement, including items on input data, obligations, ownership of data, terms, authorship, all subgroup analyses and publications. All anonymous data were transferred to a secured database at the Erasmus University Medical Center Rotterdam. Upon receiving the data, a thorough check of the data took place by reproducing the main baseline characteristics and the 
reported changes over time for the available outcome measures. Uncertainties were resolved in collaboration with the trialists.

\section{Risk of Bias assessment}

The methodological quality of all included trials in the OA Trial Bank were assessed using the twelve criteria recommended by Cochrane (see supplementary Table S1) and were evaluated independently by two researchers (JR and RR). The criteria were scored as 'yes' (low risk of bias), 'no' (high risk of bias) or 'unclear'. Any disagreement between the review authors was resolved by discussion, including input from a third review author (MvM). A study with a low risk of bias was defined as fulfilling six or more of the criteria items. In case the number of shared studies would allow proper interpretation ( $\geq 10$ studies), funnel plots were considered for evaluation of publication bias.

\section{Data analyses}

Firstly, heterogeneity of the eligible studies was determined for the primary outcomes, using a 2stage meta-analysis approach in Review Manager 5.3. In case of high heterogeneity $\left(I^{2}\right.$ index $\left.>50\right)$, sensitivity analyses without data from trials causing the heterogeneity were planned. Secondly, a descriptive comparison between studies was performed. We assumed missing data to be missing at random. Therefore missing data for covariates and outcome measures were imputed, using multiple imputation methods, within each original study. Outcomes measured on different scales were standardized in order to pool the data. Predefined subgroup factors were dichotomized, based on consensus of the OA Trial Bank Steering Committee. For this, descriptive statistics of the subgroup variables for each of the five trials were shared with the Steering Committee, together with proposed cut-off values, based on literature, data separation in the available trials and previous IPD metaanalysis by the OA Trial Bank ${ }^{10}$.

The primary outcome measures were pain severity in the short-term ( 3 to 6 months) and at longterm ( $\geq 1$ year) follow-up. Secondary outcomes were physical function and all forms of structural changes at these time points.

A one-stage multilevel regression analysis was performed to estimate the magnitude of the effect (estimated pooled mean differences) of glucosamine over the control intervention over all included studies and in the different subgroups with the individuals nested within each study. A single covariate was added to the regression models to indicate the study (fixed factor), in order to adjust for possible residual confounding by study differences. To assess possible subgroup effects, a random-effects linear regression model was used to determine interaction effects. This model included the dependent variable (primary or secondary outcome measure), the independent variable (treatment group), the effect modifier (subgroup indicator), and an interaction term (independent variable $x$ effect modifier). All analyses were adjusted for age sex, BMI, WOMAC pain at baseline and were performed with and without stratification for type of glucosamine and with and without stratification for the affected joint. Comparisons and subgroup analysis for which only one RCT was available were not taken into account, since main effects were already studied in the original publication and individual trials usually were not powered for subgroup analysis. A p-value $<0.05$ was regarded as statistically significant in all analyses, using IBM SPSS software version 22.

\section{$\underline{\text { Results }}$}

The literature search resulted in 1377 abstracts. After screening, 58 publications were evaluated in full-text and 18 fulfilled all inclusion criteria ${ }^{12-29}$, with two additional trials identified from the 
references of the included trials ${ }^{30,31}$ (Figure 1). Searching the clinical trial registries resulted in one additional potentially eligible trial (NCT01074476). All 21 corresponding authors of these trials were contacted for participation. After multiple efforts to contact all data owners of the eligible trials, authors/institutes of six studies agreed to participate and delivered trial data to the OA Trial Bank ${ }^{14-16 \text {, }}$ $24,28,29$. Corresponding authors of two trials indicated that trial data were no longer available ${ }^{13,23}$. Two corresponding authors did reply positively to the initial request for data sharing, but a signed license agreement was never received ${ }^{12,20}$. One corresponding author was not interested in participation ${ }^{17}$. No contact was established with any of the authors nor the research institutes of five studies $18,21,26,30,31$ and the one study identified in the clinical trial registry. Four data owners indicated that they were not permitted to share their data by the study sponsor ${ }^{19,22,25,27}$. See Table 1 for full details of all eligible studies.

Five out of the six studies willing to participate involved knee OA participants ${ }^{14-16,24,29}$, while only one involved hip OA participants ${ }^{28}$. Follow-up duration in the six trials ranged from 3 to 24 months. Three studies evaluated glucosamine sulphate (GS) ${ }^{15,16,28}$ and two glucosamine hydrochloride (GH) ${ }^{14}$, 29 . The publication of the remaining study stated that the first 163 subjects received GS, but that the subsequent subjects received $\mathrm{GH}^{24}$. However, after extensive communication with the trial owner, the order of glucosamine type was deemed to be a typographical error, since the supplier of the glucosamine for the latter part of the participants (Rottapharm) is renowned for its GS. Data on participants within this trial were allocated to the stratified analysis for glucosamine type based upon this new insight of the glucosamine type provided. With the exception of the trial by Coulson et al. that used green-lipped mussel extract as comparison ${ }^{15}$, all studies compared their glucosamine substrate against placebo. The trial by Coulson et al. was therefore not included in the subgroup analysis (mean change in WOMAC pain -1.6 [-3.7 to 0.6] on a 0 to 20 scale in favour of glucosamine [p $=0.157])^{15}$. The trial by Sawitzke et al. ${ }^{29}$ presented long-term follow-up from the Clegg et al. ${ }^{14}$, but since both publications report on different outcome measures of interest (clinical data and radiography vs. clinical data only) and risk of bias could be assessed for both publications separately, both were indicated as separate trials. No important issues were identified when checking shared trial data, but for the trial by McAlindon ${ }^{24}$ for which data of the first 199 (out of 205 in the original publication) could be retrieved by the trial owners. No relevant differences in baseline characteristics for the subjects with shared data and the published data were observed. Percentages of missing data for the main baseline characteristics and all outcome measures for each of the five individual trials are presented in supplementary Table S2. All listed variables were used in the multiple imputation by the SPSS software package, creating 20 imputed data sets for each trial.

The five trials included in the analysis included a total number of 1625 participants (64\% women), 815 randomised to glucosamine and 810 to placebo. This reflected $55 \%$ of the participants randomized in the 17 published RCTs on glucosamine versus placebo. Pain was measured in all five studies using the ordinal WOMAC questionnaire ${ }^{32}$. Scores were rescaled to a 0-100 scale and defined at short-term (closest to a minimal of 3 months follow-up) for the trials by McAlindon et al. ${ }^{24}$, Clegg et al. ${ }^{14}$, and Rozendaal et al. ${ }^{28}$ and long-term ( 2 years follow-up) for Fransen et al. ${ }^{16}$, Sawitzke et al. ${ }^{29}$, and Rozendaal et al. ${ }^{28}$. Physical function was also measured in all five studies using the WOMAC questionnaire and was rescaled and defined in an identical matter. Figure 2 presents the overall mean differences of these five trials for the primary outcome at short and long-term, based on the imputed data sets. 
The following subgroups were defined: WOMAC pain $<70 \mathrm{vs.} \geq 70, \mathrm{BMI}<27 \mathrm{~kg} / \mathrm{m}^{2} \mathrm{vs}$. $\geq 27 \mathrm{~kg} / \mathrm{m}^{2}$, Kellgren \& Lawrence grade ${ }^{33}$ (KL) 0-2 vs. KL3-4, and presence vs. absence of inflammation. Presence of inflammation was defined as either presence of swelling/effusion on clinical examination ${ }^{14,29}$ or an elevated erythrocyte sedimentation rate $(E S R)^{28}$, defined as ESR $\geq 20 \mathrm{~mm} / \mathrm{h}$ for men aged $\geq 50$ years, ESR $\geq 15 \mathrm{~mm} / \mathrm{h}$ for men aged $<50$ years, ESR $\geq 30 \mathrm{~mm} / \mathrm{h}$ for women aged $\geq 50$ years, and ESR $\geq 20$ $\mathrm{mm} / \mathrm{h}$ for women aged $<50$ years. Inflammation data were only available when combining data from one knee $\mathrm{OA}^{14,29}$ and one hip $\mathrm{OA}$ trial ${ }^{28}$. Therefore, no additional stratification was possible. Baseline Kellgren and Lawrence grades were only available in one knee OA trial with short-term outcomes ${ }^{14}$, two knee OA trials with long-term outcomes ${ }^{16,29}$, and the one hip OA trial ${ }^{28}$ with short and longterm outcomes. Given this lack of consistency, stratification of the subgroup analysis was done for knee OA trials only on long-term outcomes.

\section{Risk of bias and heterogeneity}

All five studies were defined as having a low risk of bias (Table 2 ) and heterogeneity was low $\left(1^{2}=0\right.$ for main effects on pain at short and $\mathrm{I}^{2}=14$ for long-term follow-up, see Figure 2 ), so no sensitivity analyses were performed.

\section{Overall intervention effects}

Estimated pooled differences for the primary and secondary outcome measures are presented in Table 3. No statistical significance main effects were found for glucosamine over placebo.

\section{Subgroup effects}

None of the interaction terms of the predefined subgroups reached statistical significance (see Table 3). Estimated pooled differences within each subgroup for the primary outcomes over all eligible trials are presented in Figure 3. Within the stratified analyses among studies using GS for knee OA the number of subjects with high baseline pain was too small for the software to test the pooled interaction term for the baseline pain severity subgroup.

\section{$\underline{\text { Discussion }}$}

To our knowledge, this is the first IPD meta-analysis to examine potential subgroup effects of oral glucosamine for people with OA. Within the 5 trials where the authors were willing to share their data, 1625 patients with knee or hip OA were analysed. This represents $55 \%$ of all available participants from the placebo controlled trials for this product. The main findings are: [1] overall, glucosamine was no better than placebo for both pain and function outcomes; [2] in subgroup analyses, glucosamine was no better than placebo according to baseline pain severity, BMI, gender, structural abnormalities, and presence of inflammation; and [3] the majority of trials were knee OA (4 trials, 1403 patients) and the analysis based on knee OA only had similar results.

Several systematic reviews and network meta-analyses have shown that as the number of highquality and industry-independent studies on the effectiveness of glucosamine for OA increased over time, the results of earlier studies that showed beneficial effects of glucosamine were viewed as less credible $^{3-5,8,34,35}$. It is therefore not surprising that the present IPD meta-analysis also showed no significant main effects, especially since previous studies showed a low risk of bias to be associated with small, non-significant effect sizes for glucosamine over placebo ${ }^{3,8,34}$ and the fact that all included studies had a low risk of bias. Present results of overall treatment effects within the trials that shared data and over the different stratifications ranged from -0.43 to 2.02 on the 0 to 100 WOMAC pain scale, which is comparable to the overall treatment effects for industry independent 
studies ( 0.1 [ $95 \% \mathrm{Cl}-0.2$ to 0.5$]$ for VAS pain on a 0 to 10 scale) presented by the meta-analyses of Wandel and colleagues ${ }^{3}$. In the literature, overall beneficial effects of treatment have been reported in studies using the glucosamine compound produced by Rottapharm ${ }^{4,5,8,34}$, however these trials were not made available to the study team for the current analyses.

Extending previous initiatives, the present study also evaluated treatment effects of glucosamine over placebo for several clinically relevant subgroups of OA, made possible by the IPD from the collaborating trials. Despite the large number of participants incorporated in the IPD meta-analysis, none of the interaction terms reached statistical significance. The interactions with BMI among knee OA patients receiving GS on short-term function $(p=0.12)$ and on long-term pain $(p=0.10)$ were the only outcomes for which further research may be warranted. However, given the number of analyses performed in the study incidental findings are certainly possible.

The currently used cut-off for the baseline pain severity subgroup is somewhat comparable to the strata used in the Clegg et al. study ${ }^{14}$ to test for different effects within subjects with mild pain (WOMAC pain scores 0 to 60 ) versus those with moderate to severe pain (WOMAC pain scores 60 to 80). The Clegg et al. study was not powered to show subgroup effects, but the non-significant effects of glucosamine over placebo within both subgroups is corroborated by the present results.

The current study has several limitations. Despite all efforts, data from only six of the 21 identified studies were acquired. Of those studies not included in the present study, the largest groups were those not responding to any of the requests for data sharing ( 6 studies) and those not permitted by the commercial study sponsor to share data (4 studies), see Table 1. Although missing data for the main baseline characteristics within the data shared with the OA Trial Bank were limited, multiple imputation methods were needed to deal with the missing data in the outcome measures that ranged from $2 \%$ to $46 \%$. Within the trials that shared data, only a few measured the pre-defined subgroups based on structural abnormalities and presence of inflammation. The available data for these subgroups combined studies evaluating different glucosamine substances for different $O A$ joints. Therefore, rigorous stratification of the analysis was not possible with the available data.

Open access to data of clinical trials has been proposed and debated for several years ${ }^{36-38}$. Nevertheless our experience, in common with others, suggests that currently this is far from accepted practice ${ }^{39}$. Thus the full potential and use of completed clinical trials is not reached and only part of the clinical evidence is available to clinicians and patients, thus threatening the appropriateness of recommendations for clinical decision-making ${ }^{39}$. Once initiatives such as the OA Trial Bank, which appropriately use existing data for scientific purposes, become more established and generally accepted, authors and commercial parties involved in clinical research may become more confident in data sharing. The OA Trial Bank plans to update publications every five years and will again approach data owners that chose to not share their data to the OA Trial Bank in the first initiative.

The aim of the present study was to perform an IPD meta-analysis on all available RCTs on glucosamine in people with OA. After performing the systematic search of the literature and clinical trial registers, it took 18 months to reach as many data owners as possible and to collect and check all data of those willing to deliver their trial data. For a systematic review, one might argue that an update of the search strategy is warranted. However, given the time-consuming efforts of sharing data between research institutes, this was not feasible for the present study. 
In conclusion, the current IPD on the efficacy of glucosamine for subgroups of OA based on pain severity, BMI, sex, radiographic structural changes, and presence of inflammation, using data from $55 \%$ of the participants available in literature and using data from low risk-of-bias trials only, did not identify a subgroup for which glucosamine showed any significant beneficial effects over placebo for pain or function in either the short- or long-term. Stratification only for participants with knee OA or for type of glucosamine did not result in any differences in outcomes. Therefore, currently there is no evidence to support the use of glucosamine for treatment of hip or knee OA in general, and an absence of evidence to support the use of glucosamine for clinically relevant subgroups of OA according to baseline pain severity, BMI, sex, structural abnormalities, and presence of inflammation.

\section{Acknowledgements}

All data owners (researchers and institutes) are to be acknowledged for providing their data to the OA Trial Bank.

\section{Funding sources}

The current project received funding by the Dutch Arthritis Foundation (BP12-1-161). KSD is part funded by the National Institute for Health Research (NIHR) Collaborations for Leadership in Applied Research and Care West Midlands and by a Knowledge Mobilisation Research Fellowship (KMRF-2014-03-002) from the NIHR. This paper presents independent research funded by the National Institute for Health Research (NIHR). The views expressed are those of the author(s) and not necessarily those of the NHS, the NIHR or the Department of Health. WZ is supported by a grant from Arthritis Research UK. TEM is supported by grants from Sanofi Aventis, Abbvie, Fidia, Samumed, and Pfizer and personal fees from Flexion Therapeutics, Samumed, Plexxikon Inc, Regeneron, Orthogen, and McNeil Consumer HC. LSL is supported by personal fees from Galapagos NV, Flexion Therapeutics, Johnson \& Johnson, Regeneron, Össur, and Samumed.

Role of the funding bodies

None of the funding bodies had a role in the study design, in the collection, analysis and interpretation of the data, in writing of the manuscript, or in the decision to submit the manuscript for publication.

\section{Competing interest}

All authors have completed the ICMJE uniform disclosure form and declare no financial relationships with any organisations that might have an interest in the submitted work.

\section{Contributions to the work}

JR, MvM, JWB, MD, KSD, LSL, TEM, WZ and SBZ have substantially contributed to the conception and design of the work. JR and RR have substantially contributed to the acquisition of the data and drafted the manuscript. All authors contributed to the analysis and interpretation of the work, revised the manuscript critically for important intellectual content, approved the final version of the manuscript, and agreed to be accountable for all aspects of the work.

\section{Study data}

All authors had full access to all of the data and can take responsibility for the integrity of the data and the accuracy of the analysis. Individual Patient Data from included studies only available upon approval of the trial owners and the Steering Committee of the OA Trial Bank. 


\section{Transparency declaration}

$J R, M v M$ and SBZ affirm that the manuscript is an honest, accurate, and transparent account of the study being reported. No important aspects of the study have been omitted and any discrepancy from the study as planned have been explained.

\section{Patient involvement}

Two representatives of patient and public involvement (members of the Arthritis research UK OA Research Users Group) are official members of the Steering Committee of the OA Trial Bank. These representatives provided feedback on the design of the study, including study selection, selection and definitions of subgroups, and outcome measures. Also for dissemination activities of OA Trial Bank and for prioritization of future research questions, the input from patient and public involvement is obtained. 
Figure 1. Study flow chart

Figure 2. Forest plots for mean change in WOMAC pain at short-term (upper panel) and long-term (lower panel) on a 0 to 100 scale for studies that shared trial data.

Figure 3. Estimated pooled differences between glucosamine and placebo within pre-defined subgroups for all eligible trials. Positive values indicate a greater reduction in the outcome measure for glucosamine. Red figures represent low pain (WOMAC pain $<70)$, low BMI $\left(<27 \mathrm{~kg} / \mathrm{m}^{2}\right)$, male sex, $K \& L$ grades $0-2$, and absence of inflammation subgroups, respectively. Blue figures represent high pain (WOMAC pain $\geq 70$ ), high BMI ( $\geq 27 \mathrm{~kg} / \mathrm{m}^{2}$ ), female sex, $K \& L$ grades $3-4$, and presence of inflammation subgroups, respectively. 
Table 1. Characteristics of all eligible and contacted studies (stratified for authors' reply on data sharing request).

\begin{tabular}{|c|c|c|c|c|c|c|c|c|}
\hline & Origin & Participants & $\begin{array}{l}\mathrm{N} \text { in } \\
\text { control } \\
\text { group }\end{array}$ & $\begin{array}{l}\mathrm{N} \text { in } \\
\text { Glucosamine } \\
\text { group }\end{array}$ & Interventions & Follow-up & Funding source & $\begin{array}{l}\text { Reply to data } \\
\text { sharing } \\
\text { request }\end{array}$ \\
\hline Clegg et al. $2006^{14}$ & USA & knee OA & 313 & 317 & $\begin{array}{l}\text { GH vs. CS vs. GH+CS vs. } \\
\text { placebo vs. Celecoxib }\end{array}$ & 6 months & Funding agency & $\begin{array}{l}\text { Data delivered } \\
\text { to OA Trial } \\
\text { Bank }\end{array}$ \\
\hline $\begin{array}{l}\text { Coulson et al. } \\
2013^{15}\end{array}$ & Australia & knee OA & 21 & 17 & $\begin{array}{l}\text { GS vs. green-lipped } \\
\text { mussel extract }\end{array}$ & 3 months & Commercial party & $\begin{array}{l}\text { Data delivered } \\
\text { to OA Trial } \\
\text { Bank }\end{array}$ \\
\hline $\begin{array}{l}\text { Fransen et al. } \\
2015^{16}\end{array}$ & Australia & knee OA & 151 & 152 & $\begin{array}{l}\text { GS vs. GS+CS vs. CS vs. } \\
\text { placebo }\end{array}$ & 24 months & $\begin{array}{l}\text { Governmental institution } \\
\text { and by some } \\
\text { supplementary funding } \\
\text { from a commercial party }\end{array}$ & $\begin{array}{l}\text { Data delivered } \\
\text { to OA Trial } \\
\text { Bank }\end{array}$ \\
\hline $\begin{array}{l}\text { McAlindon et al. } \\
2004^{24}\end{array}$ & USA & knee OA & 104 & 101 & GH vs. placebo ${ }^{* * *}$ & 3 months & Funding agency & $\begin{array}{l}\text { Data delivered } \\
\text { to OA Trial } \\
\text { Bank }\end{array}$ \\
\hline $\begin{array}{l}\text { Rozendaal et al. } \\
2008^{28}\end{array}$ & $\begin{array}{l}\text { The } \\
\text { Netherlands }\end{array}$ & hip OA & 111 & 111 & GS vs. placebo & 24 months & Governmental institution & $\begin{array}{l}\text { Data delivered } \\
\text { to OA Trial } \\
\text { Bank }\end{array}$ \\
\hline $\begin{array}{l}\text { Sawitzke et al. } \\
2010^{29^{* *}}\end{array}$ & USA & knee OA & 131 & 134 & $\begin{array}{l}\text { GH vs. CS vs. GH+CS vs. } \\
\text { placebo vs. Celecoxib }\end{array}$ & 24 months & Governmental institution & $\begin{array}{l}\text { Data delivered } \\
\text { to OA Trial } \\
\text { Bank }\end{array}$ \\
\hline $\begin{array}{l}\text { Cibere et al. } \\
2004^{13}\end{array}$ & Canada & knee OA & 66 & 71 & GS vs. placebo & 6 months & Funding agency & $\begin{array}{l}\text { Data no longer } \\
\text { available }\end{array}$ \\
\hline $\begin{array}{l}\text { Martí-Bonmatí et } \\
\text { al. } 2009^{23}\end{array}$ & Spain & knee OA & 4 & 7 & GS vs. acetaminophen & 6 months & Commercial party & $\begin{array}{l}\text { Data no longer } \\
\text { available }\end{array}$ \\
\hline $\begin{array}{l}\text { Chopra et al. } \\
2011^{12}\end{array}$ & India & knee OA & 35 & 35 & $\begin{array}{l}\text { Five herbal groups vs. } \\
\text { GS vs. placebo }\end{array}$ & 4 months & Governmental institution & $\begin{array}{l}\text { Positive to first } \\
\text { request, but } \\
\text { no data } \\
\text { delivery }\end{array}$ \\
\hline
\end{tabular}




\begin{tabular}{|c|c|c|c|c|c|c|c|c|}
\hline $\begin{array}{l}\text { Hughes and Carr } \\
2002^{20}\end{array}$ & UK & knee OA & 40 & 40 & GS vs. placebo & 6 months & Unknown & $\begin{array}{l}\text { Positive to first } \\
\text { request, but } \\
\text { no data } \\
\text { delivery }\end{array}$ \\
\hline $\begin{array}{l}\text { Frestedt et al. } \\
2008^{17}\end{array}$ & USA & knee OA & 16 & 19 & $\begin{array}{l}\text { GS vs. Placebo vs. } \\
\text { Aquamin vs. } \\
\text { Aquamin+GS }\end{array}$ & 3 months & Commercial party & $\begin{array}{l}\text { Not interested } \\
\text { in } \\
\text { participation }\end{array}$ \\
\hline $\begin{array}{l}\text { Giordano et al. } \\
2009^{31}\end{array}$ & Italy & knee OA & 30 & 30 & GS vs. placebo & 3 months & Unknown & $\begin{array}{l}\text { No contact } \\
\text { with authors/ } \\
\text { institutions }\end{array}$ \\
\hline $\begin{array}{l}\text { Hatano et al. } \\
2006^{18}\end{array}$ & Japan & knee OA & 31 & 36 & $\begin{array}{l}\text { Soymilk with vs } \\
\text { without } N \text {-acetyl } \\
\text { glucosamine }\end{array}$ & 3 months & Unknown & $\begin{array}{l}\text { No contact } \\
\text { with authors/ } \\
\text { institutions }\end{array}$ \\
\hline $\begin{array}{l}\text { Kawakasi et al. } \\
2008^{21}\end{array}$ & Japan & knee OA & 42 & 49 & $\begin{array}{l}\text { Home exercise vs. } \\
\text { home exercise+GH vs. } \\
\text { home } \\
\text { exercise+risedronate }\end{array}$ & 18 months & Unknown & $\begin{array}{l}\text { No contact } \\
\text { with authors/ } \\
\text { institutions }\end{array}$ \\
\hline NCT01074476* & Canada & knee OA & 10 & 10 & GS vs. placebo & 3 months & Governmental institution & $\begin{array}{l}\text { No contact } \\
\text { with authors/ } \\
\text { institutions }\end{array}$ \\
\hline $\begin{array}{l}\text { Petersen et al. } \\
2011^{26}\end{array}$ & Denmark & knee OA & 12 & 12 & $\begin{array}{l}\text { GS vs. placebo vs. } \\
\text { ibuprofen }\end{array}$ & 3 months & $\begin{array}{l}\text { Governmental institution, } \\
\text { and funding agency }\end{array}$ & $\begin{array}{l}\text { No contact } \\
\text { with authors/ } \\
\text { institutions }\end{array}$ \\
\hline $\begin{array}{l}\text { Usha and Naidu } \\
2004^{30}\end{array}$ & India & knee OA & 28 & 30 & $\begin{array}{l}\text { G vs. MSM vs. G + } \\
\text { MSM vs. placebo }\end{array}$ & 3 months & Commercial party & $\begin{array}{l}\text { No contact } \\
\text { with authors/ } \\
\text { institutions }\end{array}$ \\
\hline $\begin{array}{l}\text { Herrero- } \\
\text { Beaumont et al. } \\
2007^{19}\end{array}$ & $\begin{array}{l}\text { Spain/ } \\
\text { Portugal }\end{array}$ & knee OA & 104 & 106 & $\begin{array}{l}\text { Crystalline GS vs. } \\
\text { placebo vs. } \\
\text { acetaminophen }\end{array}$ & 6 months & Commercial party & $\begin{array}{l}\text { Data sharing } \\
\text { not allowed by } \\
\text { study sponsor }\end{array}$ \\
\hline $\begin{array}{l}\text { Kwoh et al. } \\
2014^{22}\end{array}$ & USA & knee OA & 103 & 98 & GH vs. placebo & 6 months & Commercial party & $\begin{array}{l}\text { Data sharing } \\
\text { not allowed by } \\
\text { study sponsor }\end{array}$ \\
\hline
\end{tabular}




\begin{tabular}{|c|c|c|c|c|c|c|c|c|}
\hline $\begin{array}{l}\text { Pavelká et al. } \\
2002^{25}\end{array}$ & $\begin{array}{l}\text { Czech } \\
\text { Republic }\end{array}$ & knee OA & 101 & 101 & $\begin{array}{l}\text { Crystalline GS vs. } \\
\text { placebo }\end{array}$ & 36 months & Commercial party & $\begin{array}{l}\text { Data sharing } \\
\text { not allowed by } \\
\text { study sponsor }\end{array}$ \\
\hline $\begin{array}{l}\text { Reginster et al. } \\
2001^{27}\end{array}$ & Belgium & knee OA & 106 & 106 & GS vs. placebo & 36 months & Commercial party & $\begin{array}{l}\text { Data sharing } \\
\text { not allowed by } \\
\text { study sponsor }\end{array}$ \\
\hline
\end{tabular}

*Trial identified in trial registry, no publication available; **long-term follow-up of Clegg et al.; ${ }^{* * *}$ The first 163 patients were randomized over placebo and

3 glucosamine hydrochloride, the remaining subjects over placebo and glucosamine sulphate; N: number of patients randomized to the specific group; GS =

4 glucosamine sulphate; GH = glucosamine hydrochloride; CS = chondroitin sulphate; G = unknown which glucosamine substance; MSM:

5 methylsulfonylmethane. 
Table 2. Risk of bias assessment of studies included in glucosamine vs. placebo comparison.

\begin{tabular}{|c|c|c|c|c|c|c|c|c|c|c|c|c|c|}
\hline & A1 & B2 & C3 & $\mathrm{C} 4$ & C5 & D6 & D7 & E8 & E9 & E10 & E11 & E12 & Total \\
\hline Clegg et al. $2006^{14}$ & + & + & + & + & + & + & + & + & + & + & + & + & Low risk \\
\hline Fransen et al. $2015^{16}$ & + & + & + & + & + & + & + & + & + & $?$ & + & + & Low risk \\
\hline McAlindon et al. $2004^{24}$ & $?$ & + & + & + & + & + & + & - & + & + & + & + & Low risk \\
\hline Rozendaal et al. $2008^{28 *}$ & + & + & + & + & + & + & + & + & + & + & + & + & Low risk \\
\hline Sawitzke et al. $2010^{29}$ & + & + & + & + & + & - & + & + & + & + & + & + & Low risk \\
\hline
\end{tabular}

7 + yes (low risk of bias); - no (high risk of bias); ? unclear; A1. Method of randomization adequate; B2.

8 Treatment allocation concealed; C3. Patient blinded to the intervention; $\mathrm{C} 4$. Care provider blinded to

9 the intervention; $\mathrm{C5}$. Outcome assessor blinded to the intervention; D6. Drop-out rate described and 10 acceptable; D7; Randomized participants analysed in the group to which they were allocated; E8.

11 Groups similar at baseline regarding the most important prognostic indicators; E9. Co-interventions 12 avoided or similar; E10. Compliance acceptable; E11. Timing of the outcome assessment similar in all 13 groups; E12 Selective outcome reporting. Overall, low risk of bias was defined as fulfilling six or more 14 of the criteria items. *scored by JR and MvM due to study involvement of RR. 
Table 3. Estimated pooled differences $(95 \% \mathrm{Cl})$ between glucosamine and placebo on a 0-100 scale (positive values indicate a greater reduction in the outcome measure for glucosamine) and $p$-values for treatment-subgroup interactions.

\begin{tabular}{|c|c|c|c|c|c|c|}
\hline & & $\begin{array}{l}\text { All studies } \\
\text { ( } \mathrm{N}=1625 \text { in } 5 \\
\text { studies) }\end{array}$ & $\begin{array}{l}\text { Knee OA only } \\
\begin{array}{c}\text { ( }=1403 \text { in } 4 \\
\text { studies) }\end{array}\end{array}$ & $\begin{array}{l}\text { GH in knee OA } \\
\begin{array}{c}\text { (N = } 1058 \text { in } 3 \\
\text { studies) }\end{array}\end{array}$ & $\begin{array}{c}\text { GS in knee } \\
\text { and hip OA } \\
\text { ( } N=567 \text { in } 3 \\
\text { studies) }\end{array}$ & $\begin{array}{l}\text { GS in knee OA } \\
\text { (N = } 345 \text { in } 2 \\
\text { studies) }\end{array}$ \\
\hline \multirow{8}{*}{ 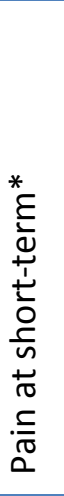 } & \multicolumn{6}{|c|}{ Estimated pooled differences and $95 \%$ confidence interval } \\
\hline & $\begin{array}{l}\text { Glucosamine vs } \\
\text { placebo }\end{array}$ & $\begin{array}{c}0.60 \\
(-1.80 \text { to } 3.00)\end{array}$ & $\begin{array}{c}0.91 \\
(-1.91 \text { to } 3.75)\end{array}$ & $\begin{array}{c}0.98 \\
(-1.94 \text { to } 3.91)\end{array}$ & $\begin{array}{c}-0.43 \\
(-4.44 \text { to } 3.58)\end{array}$ & $\begin{array}{c}0.59 \\
(-11.79 \text { to } 12.98)\end{array}$ \\
\hline & \multicolumn{6}{|c|}{$p$-values for treatment-subgroup interactions } \\
\hline & Pain subgroup ${ }^{a}$ & 0.77 & 0.97 & 0.80 & 0.17 & $-f$ \\
\hline & BMI subgroup ${ }^{b}$ & 0.31 & 0.62 & 0.56 & 0.41 & 0.89 \\
\hline & Sex subgroup ${ }^{c}$ & 0.68 & 0.59 & 0.68 & 0.86 & 0.68 \\
\hline & KL subgroup ${ }^{d}$ & 0.75 & - & - & - & - \\
\hline & $\begin{array}{l}\text { Inflammation } \\
\text { subgroup }^{\mathrm{e}}\end{array}$ & 0.92 & - & - & - & - \\
\hline \multirow{8}{*}{ 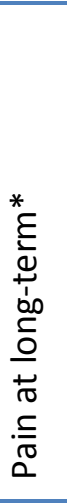 } & \multicolumn{6}{|c|}{ Estimated pooled differences and 95\% confidence interval } \\
\hline & $\begin{array}{l}\text { Glucosamine vs } \\
\text { placebo }\end{array}$ & $\begin{array}{c}0.98 \\
(-1.76 \text { to } 3.73)\end{array}$ & $\begin{array}{c}0.19 \\
(-2.83 \text { to } 3.22)\end{array}$ & $\begin{array}{c}0.78 \\
(-4.33 \text { to } 5.89)\end{array}$ & $\begin{array}{c}1.22 \\
(-1.90 \text { to } 4.33)\end{array}$ & $\begin{array}{c}-0.38 \\
(-3.67 \text { to } 2.90)\end{array}$ \\
\hline & \multicolumn{6}{|c|}{$p$-values for treatment-subgroup interactions } \\
\hline & Pain subgroup ${ }^{a}$ & 0.26 & 0.28 & 0.42 & 0.44 & 0.86 \\
\hline & BMI subgroup ${ }^{b}$ & 0.55 & 0.10 & 0.51 & 0.72 & 0.10 \\
\hline & Sex subgroup ${ }^{c}$ & 0.46 & 0.53 & 0.75 & 0.52 & 0.77 \\
\hline & KL subgroup ${ }^{d}$ & 0.72 & 0.40 & - & - & - \\
\hline & $\begin{array}{l}\text { Inflammation } \\
\text { subgroup }^{\mathrm{e}}\end{array}$ & 0.23 & - & - & - & - \\
\hline \multirow{8}{*}{ 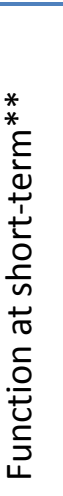 } & \multicolumn{6}{|c|}{ Estimated pooled differences and 95\% confidence interval } \\
\hline & Glucosamine vs & 1.74 & 1.80 & 1.92 & 1.23 & -0.39 \\
\hline & \multicolumn{6}{|c|}{$p$-values for treatment-subgroup interactions } \\
\hline & Pain subgroup ${ }^{a}$ & 0.47 & 0.34 & 0.37 & 0.69 & $-f$ \\
\hline & BMI subgroup ${ }^{b}$ & 0.87 & 0.83 & 0.64 & 0.38 & 0.12 \\
\hline & Sex subgroup ${ }^{c}$ & 0.47 & 0.30 & 0.39 & 0.91 & 0.34 \\
\hline & KL subgroup ${ }^{d}$ & 0.96 & - & - & - & - \\
\hline & $\begin{array}{l}\text { Inflammation } \\
\text { subgroup }^{\mathrm{e}}\end{array}$ & 0.37 & - & - & - & - \\
\hline \multirow{9}{*}{ 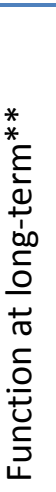 } & \multicolumn{6}{|c|}{ Estimated pooled differences and 95\% confidence interval } \\
\hline & Glucosamine vs & 1.40 & 0.63 & 0.85 & 2.02 & 0.62 \\
\hline & placebo & $(-1.27$ to 4.06$)$ & $(-2.31$ to 3.58$)$ & $(-4.43$ to 6.13$)$ & $(-0.82$ to 4.86$)$ & $(-2.29$ to 3.52$)$ \\
\hline & \multicolumn{6}{|c|}{$p$-values for treatment-subgroup interactions } \\
\hline & Pain subgroup ${ }^{a}$ & 0.49 & 0.38 & 0.55 & 0.94 & 0.91 \\
\hline & BMI subgroup ${ }^{b}$ & 0.82 & 0.42 & 0.65 & 0.56 & 0.68 \\
\hline & Sex subgroup ${ }^{c}$ & 0.72 & 0.61 & 0.80 & 1.00 & 0.94 \\
\hline & KL subgroup ${ }^{d}$ & 0.83 & 0.77 & - & - & - \\
\hline & $\begin{array}{l}\text { Inflammation } \\
\text { subgroup }^{\text {e }}\end{array}$ & 0.46 & - & - & - & - \\
\hline
\end{tabular}


*measured using WOMAC pain (0-100) and adjusted for age sex, BMI, WOMAC pain at baseline and study number. ${ }^{* *}$ measured using WOMAC function (0-100) and adjusted for age sex, BMI, WOMAC function at baseline and study number. Positive estimated pooled differences indicate a greater reduction in the outcome in the glucosamine group compared to the placebo group. ${ }^{\text {a } W O M A C}$ pain $<70$ vs. $\geq 70$ on a $0-100$ scale. ${ }^{b} \mathrm{BMI}<27 \mathrm{~kg} / \mathrm{m}^{2}$ vs. $\geq 27 \mathrm{~kg} / \mathrm{m}^{2} .{ }^{\mathrm{c}}$ male vs. female. ${ }^{\mathrm{d}}$ Kellgren \& Lawrence grades 0-2 vs. 3-4 (not available in McAlindon et al. ${ }^{24}$ ). ${ }^{\text {e }}$ Presence of inflammation, defined as presence of swelling/effusion on clinical examination or an elevated erythrocyte sedimentation rate (ESR), defined as ESR $\geq 20 \mathrm{~mm} / \mathrm{h}$ for men aged $\geq 50$ years, ESR $\geq 15 \mathrm{~mm} / \mathrm{h}$ for men aged $<50$ years, ESR $\geq 30 \mathrm{~mm} / \mathrm{h}$ for women aged $\geq 50$ years, and ESR $\geq 20 \mathrm{~mm} / \mathrm{h}$ for women aged $<50$ years, vs. absence of inflammation (not available in McAlindon et al. ${ }^{24}$ and Fransen et al. ${ }^{16}$ ). ${ }^{f}$ Too few cases in high pain group for the software to test the interaction term.

18. 
1. Zhang W, Nuki G, Moskowitz RW, Abramson S, Altman RD, Arden NK, et al. OARSI recommendations for the management of hip and knee osteoarthritis: part III: Changes in evidence following systematic cumulative update of research published through January 2009. Osteoarthritis Cartilage 2010; 18: 476-499.

2. National Clinical Guideline C. 2014.

3. Wandel S, Juni P, Tendal B, Nuesch E, Villiger PM, Welton NJ, et al. Effects of glucosamine, chondroitin, or placebo in patients with osteoarthritis of hip or knee: network meta-analysis. BMJ 2010; 341: c4675.

4. Vlad SC, LaValley MP, McAlindon TE, Felson DT. Glucosamine for pain in osteoarthritis: why do trial results differ? Arthritis Rheum 2007; 56: 2267-2277.

5. McAlindon TE, LaValley MP, Gulin JP, Felson DT. Glucosamine and chondroitin for treatment of osteoarthritis: a systematic quality assessment and meta-analysis. JAMA 2000; 283: 14691475.

6. Bierma-Zeinstra SM, Verhagen AP. Osteoarthritis subpopulations and implications for clinical trial design. Arthritis Res Ther 2011; 13: 213.

7. Zhang W, Doherty M, Arden N, Bannwarth B, Bijlsma J, Gunther KP, et al. EULAR evidence based recommendations for the management of hip osteoarthritis: report of a task force of the EULAR Standing Committee for International Clinical Studies Including Therapeutics (ESCISIT). Ann Rheum Dis 2005; 64: 669-681.

8. Towheed TE, Maxwell L, Anastassiades TP, Shea B, Houpt J, Robinson V, et al. Glucosamine therapy for treating osteoarthritis. Cochrane Database Syst Rev 2005: CD002946.

9. van Middelkoop M, Dziedzic KS, Doherty M, Zhang W, Bijlsma JW, McAlindon TE, et al. Individual patient data meta-analysis of trials investigating the effectiveness of intra-articular glucocorticoid injections in patients with knee or hip osteoarthritis: an OA Trial Bank protocol for a systematic review. Syst Rev 2013; 2: 54.

10. van Middelkoop M, Arden NK, Atchia I, Birrell F, Chao J, Rezende MU, et al. The OA Trial Bank: meta-analysis of individual patient data from knee and hip osteoarthritis trials show that patients with severe pain exhibit greater benefit from intra-articular glucocorticoids. Osteoarthritis Cartilage 2016; 24: 1143-1152.

11. Altman R, Asch E, Bloch D, Bole G, Borenstein D, Brandt K, et al. Development of criteria for the classification and reporting of osteoarthritis. Classification of osteoarthritis of the knee. Diagnostic and Therapeutic Criteria Committee of the American Rheumatism Association. Arthritis Rheum 1986; 29: 1039-1049.

12. Chopra A, Saluja M, Tillu G, Venugopalan A, Sarmukaddam S, Raut AK, et al. A Randomized Controlled Exploratory Evaluation of Standardized Ayurvedic Formulations in Symptomatic Osteoarthritis Knees: A Government of India NMITLI Project. Evid Based Complement Alternat Med 2011; 2011: 724291.

13. Cibere J, Kopec JA, Thorne A, Singer J, Canvin J, Robinson DB, et al. Randomized, doubleblind, placebo-controlled glucosamine discontinuation trial in knee osteoarthritis. Arthritis Rheum 2004; 51: 738-745.

14. Clegg DO, Reda DJ, Harris CL, Klein MA, O'Dell JR, Hooper MM, et al. Glucosamine, chondroitin sulfate, and the two in combination for painful knee osteoarthritis. N Engl J Med 2006; 354: 795-808.

15. Coulson S, Butt H, Vecchio P, Gramotnev H, Vitetta L. Green-lipped mussel extract (Perna canaliculus) and glucosamine sulphate in patients with knee osteoarthritis: therapeutic efficacy and effects on gastrointestinal microbiota profiles. Inflammopharmacology 2013; 21: 79-90.

16. Fransen $M$, Agaliotis $M$, Nairn L, Votrubec M, Bridgett L, Su S, et al. Glucosamine and chondroitin for knee osteoarthritis: a double-blind randomised placebo-controlled clinical trial evaluating single and combination regimens. Ann Rheum Dis 2015; 74: 851-858. 
17. Frestedt JL, Walsh $\mathrm{M}$, Kuskowski MA, Zenk JL. A natural mineral supplement provides relief from knee osteoarthritis symptoms: a randomized controlled pilot trial. Nutr J 2008; 7: 9.

18. Hatano K, Miyakuni Y. Effects and Safety of Soymilk Beverage Containing N-acetyl Glucosamine on Osteoarthritis. Japan Pharmacology \& Therapeutics 2006; 34: 149-165.

19. Herrero-Beaumont G, Ivorra JA, Del Carmen Trabado M, Blanco FJ, Benito P, Martin-Mola E, et al. Glucosamine sulfate in the treatment of knee osteoarthritis symptoms: a randomized, double-blind, placebo-controlled study using acetaminophen as a side comparator. Arthritis Rheum 2007; 56: 555-567.

20. Hughes R, Carr A. A randomized, double-blind, placebo-controlled trial of glucosamine sulphate as an analgesic in osteoarthritis of the knee. Rheumatology (Oxford) 2002; 41: 279284.

21. Kawasaki T, Kurosawa H, Ikeda H, Kim SG, Osawa A, Takazawa Y, et al. Additive effects of glucosamine or risedronate for the treatment of osteoarthritis of the knee combined with home exercise: a prospective randomized 18-month trial. J Bone Miner Metab 2008; 26: 279287.

22. Kwoh CK, Roemer FW, Hannon MJ, Moore CE, Jakicic JM, Guermazi A, et al. Effect of oral glucosamine on joint structure in individuals with chronic knee pain: a randomized, placebocontrolled clinical trial. Arthritis Rheumatol 2014; 66: 930-939.

23. Marti-Bonmati L, Sanz-Requena R, Rodrigo JL, Alberich-Bayarri A, Carot JM. Glucosamine sulfate effect on the degenerated patellar cartilage: preliminary findings by pharmacokinetic magnetic resonance modeling. Eur Radiol 2009; 19: 1512-1518.

24. McAlindon T, Formica M, LaValley M, Lehmer M, Kabbara K. Effectiveness of glucosamine for symptoms of knee osteoarthritis: results from an internet-based randomized double-blind controlled trial. Am J Med 2004; 117: 643-649.

25. Pavelka K, Gatterova J, Olejarova M, Machacek S, Giacovelli G, Rovati LC. Glucosamine sulfate use and delay of progression of knee osteoarthritis: a 3-year, randomized, placebocontrolled, double-blind study. Arch Intern Med 2002; 162: 2113-2123.

26. Petersen SG, Beyer N, Hansen M, Holm L, Aagaard P, Mackey AL, et al. Nonsteroidal antiinflammatory drug or glucosamine reduced pain and improved muscle strength with resistance training in a randomized controlled trial of knee osteoarthritis patients. Arch Phys Med Rehabil 2011; 92: 1185-1193.

27. Reginster JY, Deroisy R, Rovati LC, Lee RL, Lejeune E, Bruyere O, et al. Long-term effects of glucosamine sulphate on osteoarthritis progression: a randomised, placebo-controlled clinical trial. Lancet 2001; 357: 251-256.

28. Rozendaal RM, Koes BW, van Osch GJ, Uitterlinden EJ, Garling EH, Willemsen SP, et al. Effect of glucosamine sulfate on hip osteoarthritis: a randomized trial. Ann Intern Med 2008; 148: 268-277.

29. Sawitzke AD, Shi H, Finco MF, Dunlop DD, Harris CL, Singer NG, et al. Clinical efficacy and safety of glucosamine, chondroitin sulphate, their combination, celecoxib or placebo taken to treat osteoarthritis of the knee: 2-year results from GAIT. Ann Rheum Dis 2010; 69: 14591464.

30. Usha PR, Naidu MU. Randomised, Double-Blind, Parallel, Placebo-Controlled Study of Oral Glucosamine, Methylsulfonylmethane and their Combination in Osteoarthritis. Clin Drug Investig 2004; 24: 353-363.

31. Giordano N, Fioravanti A, Papakostas P, Montella A, Giorgi G, Nuti R. The efficacy and tolerability of glucosamine sulfate in the treatment of knee osteoarthritis: A randomized, double-blind, placebo-controlled trial. Curr Ther Res Clin Exp 2009; 70: 185-196.

32. Bellamy N, Buchanan WW, Goldsmith CH, Campbell J, Stitt LW. Validation study of WOMAC: a health status instrument for measuring clinically important patient relevant outcomes to antirheumatic drug therapy in patients with osteoarthritis of the hip or knee. J Rheumatol 1988; 15 : 1833-1840. 
33. Kellgren JH, Lawrence JS. Radiological assessment of osteo-arthrosis. Ann Rheum Dis 1957;

34. Eriksen P, Bartels EM, Altman RD, Bliddal H, Juhl C, Christensen R. Risk of bias and brand explain the observed inconsistency in trials on glucosamine for symptomatic relief of

35. Nuesch E, Trelle S, Reichenbach S, Rutjes AW, Burgi E, Scherer M, et al. The effects of osteoarthritis: a meta-analysis of placebo-controlled trials. Arthritis Care Res (Hoboken) 2014; 66: 1844-1855. excluding patients from the analysis in randomised controlled trials: meta-epidemiological study. BMJ 2009; 339: b3244. 